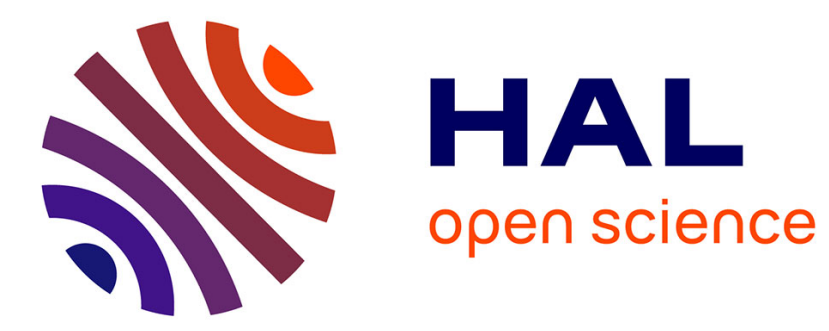

\title{
Transgenic resistance of Bulgarian potato cultivars to the Colorado potato beetle based on Bt technology
}

\author{
Ivanka Kamenova, Rossitza Batchvarova, Stanislaw Flasinski, Lidia \\ Dimitrova, Petya Christova, Slavcho Slavov, Atanas Atanassov, Plamen \\ Kalushkov, Wojciech Kaniewski
}

\section{To cite this version:}

Ivanka Kamenova, Rossitza Batchvarova, Stanislaw Flasinski, Lidia Dimitrova, Petya Christova, et al.. Transgenic resistance of Bulgarian potato cultivars to the Colorado potato beetle based on Bt technology. Agronomy for Sustainable Development, 2008, 28 (4), pp.481-488. hal-00886467

\section{HAL Id: hal-00886467 https://hal.science/hal-00886467}

Submitted on 1 Jan 2008

HAL is a multi-disciplinary open access archive for the deposit and dissemination of scientific research documents, whether they are published or not. The documents may come from teaching and research institutions in France or abroad, or from public or private research centers.
L'archive ouverte pluridisciplinaire HAL, est destinée au dépôt et à la diffusion de documents scientifiques de niveau recherche, publiés ou non, émanant des établissements d'enseignement et de recherche français ou étrangers, des laboratoires publics ou privés. 


\title{
Transgenic resistance of Bulgarian potato cultivars to the Colorado potato beetle based on Bt technology
}

\author{
Ivanka KAMENova $^{1 *}$, Rossitza BATchVArova ${ }^{1}$, Stanislaw Flasinski $^{2}$, Lidia Dimitrova $^{3}$, Petya CHRISTOvA ${ }^{1}$, \\ Slavcho Slavov ${ }^{1}$, Atanas Atanassov ${ }^{1}$, Plamen KALUSHKOV ${ }^{4}$, Wojciech KANIEWSKI ${ }^{5}$ \\ ${ }^{1}$ AgroBioInstitute, 8 Dragan Tzankov Blvd., 1164 Sofia, Bulgaria \\ ${ }^{2}$ Monsanto, GG3220, 700 Chesterfield Parkway West, St. Louis, MO 63017, USA \\ ${ }^{3}$ Potato Laboratory, 2000 Samokov, Bulgaria \\ ${ }^{4}$ Institute of Zoology, Bulgarian Academy of Sciences, 1 Zar Osvoboditel, 1000 Sofia, Bulgaria \\ ${ }^{5}$ Adam Mickiewicz University, 85 Umultowska ul. 61-614 Poznan, Poland
}

(Accepted 30 April 2008)

\begin{abstract}
Colorado potato beetle, Leptinotarsa decemlineata Say, is the most destructive insect pest of potatoes. When the population of beetles is high, plants can be completely defoliated and commercial potato production is nearly impossible without control of the beetle. The beetles have shown a tremendous ability to develop resistance against insecticides. Previously, a biotechnology approach to control Colarado potato beetle based on the use of the synthetic Bt gene was developed. In this article, a transformation procedure for three commercial Bulgarian potato cultivars was developed and potentially commercial transgenic lines have been selected based on field resistance to Colorado potato beetles and yield. Plants were transformed with the Bacillus thuringiensis (Bt) cry3A gene using Agrobacterium-mediated transformation. 110 plants from the three cultivars were regenerated and tested by double antibody sandwich enzyme-linked immunosorbent assay (DASELISA). The Cry3A protein accumulation varied across the transgenic lines, rating from very low to $71.5 \mu \mathrm{g} / \mathrm{g}$ fresh weight. 21 transgenic lines expressing the Cry3A protein at levels above $10 \mu \mathrm{g} / \mathrm{g}$ fresh weight were tested in two successive years in filed conditions at two different locations of the country. All transgenic lines compared with the controls, nontransgenic potatoes from the respective cultivar, were consistently protected from foliar damages from all developmental stages of the beetle. The comparison of all properties of the tested transgenic lines, including variety phenotypes and tuber yield, allowed the selection of the most promising 2-3 lines per cultivar. Selected lines produced tuber amounts $80-100 \%$ higher compared with the control, non-transgenic plants. Those lines were grown for mass propagation during the third year of field experiments. The presence of the transgene in these lines was confirmed with the use of primers specific to the transgene by polymerase chain reaction (PCR). Additionally, the results from the insect bioassay showed that these lines were highly resistant to insect feeding, leading to $100 \%$ of mortality of larval populations. In summary, we generated potentially commercial potato lines highly resistant to Colorado potato beetle using Bt technology that may have a profound impact on development of sustainable agriculture in Bulgaria. This is one of the several agriculture biotechnology products entirely developed and tested in Bulgaria.
\end{abstract}

potato / Bt Cry3A / Colorado potato beetle resistance / field tests / genetic transformation

\section{INTRODUCTION}

The potato, Solanum tuberosum L. is considered the fourth most important food crop in the world. Annual potato production is approaching 300 million tones and potatoes are grown on more than 18 million hectares. In Bulgaria the potato is considered a very important crop because of the percentage of acreage (11\%) used for its production and crop values.

The coleopteran Colorado potato beetle (Leptinotarsa decemlineata Say) is the insect pest that does the most damage

* Corresponding author: vanjakamenova@yahoo.com to the potato in southern and Eastern Europe, in the United States, and in Canada (Roush, 1994). The life cycle of this insect, its feeding habits and its ability to develop resistance to synthetic chemical insecticides have made the control of the beetle an increasing agricultural problem (Forgash, 1985). Complete defoliation of the crop is possible as a consequence of rapid insect population growth. Uncontrolled populations of Colorado potato beetle can reduce potato yields by at least 85\% (Roush, 1994). According to the Bulgarian Ministry of Agriculture and Forestry, even under strict plant protection regimens, about $20 \%$ of the total potato yield in the country is lost due to the beetle (unpublished). 


\begin{tabular}{|c|c|c|c|}
\hline LB & P-FMV35S/aroACP4/T-E9 & P-At.RbcS4/cry3a/T-NOS & RB \\
\hline
\end{tabular}

Figure 1. Schematic representation of T-DNA in pmon38943 used in the potato transformation. LB, left border; RB, right border; T-E9, terminator from Pisum sativum RbcS2 gene; T-NOS, terminator from nopaline synthase gene (other abbreviations explained in Materials and Methods).

Since the potato is a tetraploid, its improvement by breeding and selection is laborious and inefficient. Genetic engineering of insect-resistant cultivars provides new possibilities for sustainable pest control. Genetically improved Russet Burbank potato plants expressing the coleopteran-specific Bacillus thuringiensis $\delta$-endotoxin Cry3 A have been shown to resist Colorado potato beetle insect attack and damage (Perlak et al., 1993; Duncan et al., 2002; Kaniewski and Thomas, 2004). Other transgenic crops such as cotton, maize and eggplant, which express Bt-derived toxins, have been shown to be effective in insect population control (Benedict et al., 1996; Arpaia et al., 1997; Hamilton et al., 1997; Jansens et al., 1997). In this study, three new commercial Bulgarian potato cultivars were genetically modified by the use of Bt technology and an Agrobacterium-mediated transformation to generate resistance to the beetle.

\section{MATERIALS AND METHODS}

\subsection{Plant material}

In vitro-grown, virus-free plantlets of Solanum tuberosum cv. Kalina, Koral and Bor of seed stock from the Potato Growing Station in Samokov were used as starting material for the transformation. These three cultivars are widely grown for fresh consumption because they have shown resistance to abiotic stress in the climatic conditions in Bulgaria. Additionally, the cultivars Bor and Koral have shown very good field resistance to late blight (Phytophthora infestans) (Dimitrova and Blagoeva, 1998). The plantlets were grown in glass vials containing medium, composed of Murashige and Skoog (1962) inorganic salts, $30 \mathrm{~g} / \mathrm{L}$ sucrose, $0.17 \mathrm{~g} / \mathrm{L}$ $\mathrm{NaH}_{2} \mathrm{PO}_{4} \mathrm{H}_{2} \mathrm{O}, 0.4 \mathrm{mg} / \mathrm{L}$ thiamine- $\mathrm{HCl}$ and $10 \mathrm{mg} / \mathrm{L}$ inositol at $\mathrm{pH} 6.0$ and $7 \mathrm{~g} / \mathrm{L}$ agar. The cultures were grown at $21{ }^{\circ} \mathrm{C}$ with a photoperiod of 16:8 h light:dark and light intensity of $50-60 \mu \mathrm{Em}^{-2} \mathrm{~s}^{-1}$. The plantlets were propagated monthly by cutting two to three nodes off the top of the shoots and transferring the shoots to a fresh medium.

\subsection{Potato transformation}

The transformation vector, pMON38943 (Perlak et al., 1993), contains the Bacillus thuringiensis cry3A gene which encodes the insect-active protein driven by the Arabidopsis ribulose-1,5-bisphosphate carboxylase/oxygenase (rubisco) small subunit promoter (P-At.RbcS4) and the aroA-CP4 gene, a selectable marker for glyphosate selection driven by the FMV 35S promoter (Fig. 1). The Agrobacterium tumefaciensmediated transformation system was used mostly as described by Newell et al., (1991), except glyphosate selection was used instead of kanamycin selection.

Stem internodes about 5-8 $\mathrm{mm}$ in length and without any auxiliary buds were inoculated with the Agrobacterium tumefaciens culture containing pMON38943. The inoculated stem pieces were placed in Petri dishes on Whatman filter paper that covered the co-cultivation medium $(1 / 10$ salts, $30 \mathrm{~g} / \mathrm{L}$ sucrose and $9 \mathrm{~g} / \mathrm{L}$ agar) for two days. This was followed by transferring them to the $Z_{1}$ medium for callus induction. The $\mathrm{Z}_{1}$ medium was composed of salts plus $0.10 \mathrm{mg} / \mathrm{L}$ naphthaleneacetic acid, $5 \mathrm{mg} / \mathrm{L}$ Zeatin riboside, $30 \mathrm{~g} / \mathrm{L}$ sucrose and $9 \mathrm{~g} / \mathrm{L}$ agar. Three days later the explants were moved to a fresh $\mathrm{Z}_{1}$ medium, which also contained the selectable agent $4.23 \mathrm{mg} / \mathrm{L}$ glyphosate. After one week the explants were moved to a regeneration medium designated as $Z_{2}$, consisting of the same salts, organics and glyphosate as $Z_{1}$ medium but with $0.3 \mathrm{mg} / \mathrm{L}$ gibberellic acid $\left(\mathrm{GA}_{3}\right)$ instead of naphthaleneacetic acid. The explants were grown on the $\mathrm{Z}_{2}$ medium for four weeks, during which many of them developed shoots. The developed shoots were transferred to the $\mathrm{P}_{2}$ medium, which contained the same salt and organics as $Z_{2}$ medium without the Zeatin riboside and with $4.23 \mathrm{mg} / \mathrm{L}$ of glyphosate as a selective agent. When the shoots were $1-2 \mathrm{~cm}$ long they were cut and placed into jars containing the PM rooting medium composed of salt, $30 \mathrm{~g} / \mathrm{L}$ sucrose and $9 \mathrm{~g} / \mathrm{L}$ agar and containing $8.46 \mathrm{mg} / \mathrm{L}$ glyphosate. The media described above, $\mathrm{Z}_{1}, \mathrm{Z}_{2}, \mathrm{P}_{2}$ and $\mathrm{PM}$, also contained $750 \mathrm{mg} / \mathrm{L}$ carbenicillin and $100 \mathrm{mg} / \mathrm{L}$ cefotaxime to prevent bacterial growth. Regenerated transgenic plants were maintained and propagated in a tissue culture on media at $22{ }^{\circ} \mathrm{C}$ with a 16 hour day cycle. Propagated transgenic lines were transferred to soil for adaptation and later used to study beetle resistance in field experiments.

In each transformation, potato stem pieces which had not been inoculated with the Agrobacterium culture were used as controls and tested for the ability to produce calli and regenerate plantlets on the culture media described above with and without the presence of $4.23 \mathrm{mg} / \mathrm{L}$ glyphosate. No regeneration was observed in the explants not inoculated with Agrobacterium-carrying pMON38943 in the presence of glyphosate in the media, and the explants died.

\subsection{ELISA assays}

The accumulation of the Cry3A protein in the regenerated plants was evaluated two to three weeks after their transfer to the soil using an Enzyme-Linked Immunosorbent Assay (ELISA). Each test sample consisted of $30 \mathrm{mg}$ of leaf tissue collected from the youngest fully expanded leaves. Several dilutions (1:25, 1:500 and 1:5000 wt/vol) of analyzed leaf extract 
were used in order to compare the accumulation levels of the protein with the standard curve of purified active Cry3A protein in each microtiter plate. All the test samples and the serial dilutions of the standard protein at concentrations of 16,8 , $4,2,1,0.5$ and $0.25 \mathrm{ng} / \mathrm{mL}$ were loaded into wells in $200 \mu \mathrm{L}$ volume in duplicate. The results were read with a Humareader. The Cry3A protein concentration in tissue extracts was measured based on the standard protein concentration curve that was established in each ELISA plate using a dilution series of a purified Cry3A protein and Cry $3 \mathrm{~A}$ antibody. In total, 110 transgenic plants from three cultivars were tested. The regenerated transgenic plants that showed an expression level of the Cry3A higher than $10 \mathrm{ppm}(0.001 \mu \mathrm{g} / \mathrm{g}$ fresh weights $)$ were retained and propagated in vitro.

\subsection{Colorado potato beetle resistance field trials}

Field experiments with twenty-one transgenic lines from the three cultivars were carried out during two successive years according to the procedure described by Kaniewski and Thomas (1999). Each year the field experiments were done at different locations. The purpose of the field experiment was to evaluate the resistance of the selected transgenic potato lines to the beetle and to get preliminary agronomic data to guide future line selection for commercialization. During the first year of field experiments, plants were obtained from those propagated in vitro and adapted to the soil material. Three lines of cv. Kalina, ten lines from cv. Koral and eight lines of cv. Bor were tested in two replicated plots at two different sites in the Kostinbrod and Samokov districts. Each plot consisted of ten plants per line. The plants were spaced $20 \mathrm{~cm}$ from each other in rows $50 \mathrm{~cm}$ apart. The nontransgenic control plants of each respective cultivar were included in each plot and site. The tubers collected in the fall were stored in a climate chamber in the dark at $6-8{ }^{\circ} \mathrm{C}$ until the next spring.

During the second year of field trials, tubers collected from the first year's tests were planted at two locations in Negovan and Samokov. All lines from the first year's field tests were advanced to the second year's field tests. The tubers were divided into groups based on their size and the different replications were made with uniform seed tubers. Eighty plants per line were planted in four rows. Each line was tested in four replicates in the Samokov district, while thirty plants per line in two replicates were grown in a plot in the Negovan location. The nontransgenic control plants for the three cultivars were planted in the same number of replicates: four at the Samokov and two at the Negovan locations. The best-performing lines of each cultivar were selected in the second year of field trials.

In total, seven transgenic lines were selected based on information collected about beetle resistance, variety type and yield obtained from the two years of field experiments. Those lines were tested at one location (Samokov) during the third year of field trials. The tubers for planting were selected from the harvest from the second year's field trials.

During three years of field tests, no Colorado potato beetle insecticide was applied to any plot to ensure a high natural insect pressure. A natural beetle infestation in each field trial was also encouraged by planting the nontransgenic plants of each respective cultivar around the transgenic potato lines to attract beetles. Fertilization and chemical controls for fungal diseases and aphids were applied during the growing season. Agronomic and morphological traits such as plant phenotype, growth vigor, yield and tuber quality were evaluated.

\subsection{Transgene detection using polymerase chain reaction $(\mathbf{P C R})$}

The genomic deoxyribonucleic acid (DNA) was isolated from the seven transgenic lines which performed best under field conditions and the control plants using a protocol described by Dellaporta et al. (1983). Tissue was harvested from plants grown in vitro to ensure good-quality DNA. PCR amplification was carried out by Ready to Go PCR Beats (Amersham Pharmacia Biotech INC). The reactions were performed in a $25 \mu \mathrm{L}$ solution which consisted of $1 \mu \mathrm{L}$ of each of the primers (15 pmol), $21 \mu \mathrm{L}$ of sterile water and $2 \mu \mathrm{L}$ (100$200 \mathrm{ng}$ ) of DNA. The PCR reaction conditions for the specific primer set are listed in Table I. We chose amplification of a $300 \mathrm{bp}$ fragment of the potato adenosine 5'-triphosphate synthase gene (ATPase) as an internal positive control for PCR reactions. The amplified products were separated on $1 \%$ agarose gel by electrophoresis and visualized under $300 \mathrm{~nm}$ ultraviolet (UV) light after staining with ethidium bromide.

\subsection{Insect bioassays}

The transgenic lines' resistance to Colorado potato beetle was also tested in a laboratory bioassay. The detached leaves from the lines which performed best under field conditions, one from each cultivar $\left(\mathrm{Kalina}_{18}, \mathrm{Koral}_{12}\right.$ and Bor $4_{41}$ ), were used for the bioassay. Fifteen newly hatched first- and secondinstar larvae were placed on the upper surface of the leaves of each transgenic line and the nontransgenic control plant in $9 \mathrm{~cm}$ Petri dishes. The third- and fourth-instar larvae were reared on leaves in $18 \mathrm{~cm}$ Petri dishes. The beetle larvae were fed on nontransgenic potatoes so they would grow to specific instars before they were placed on transgenic leaves. During the insect bioassay, beetle larvae were provided with fresh potato leaves (transgenic or nontransgenic) daily. The experiment was carried out at $23 \pm 2{ }^{\circ} \mathrm{C}$, with a relative humidity of $45-72 \%$ and a 16:8 h light:dark photoperiod. The extent of feeding damage, and larval life-span and mortality were recorded. The data was analyzed by a least significant difference test (LSD) at a probability of $0.05(\alpha=0.05)$.

\section{RESULTS AND DISCUSSION}

Transformation systems for genetic engineering of potato are well established throughout the world and commonly rely on use of antibiotic resistance markers. In this research we undertook tasks to establish a transformation and selection system for Bulgarian elite potato cultivars using glyphosate. This type of selection would provide an advantage for commercialization of selected lines since no antibiotic resistance gene 
Table I. Primer sequence and amplification conditions for PCR for each gene.

\begin{tabular}{|c|c|}
\hline \multicolumn{2}{|r|}{ Bacillus thuringiensis endotoxin cry3A: expected product size: 874 bp } \\
\hline Primer 1 & 5' - ATGACTGCAGACAACAACACCGAAGCCCT - 3' \\
\hline Primer 2 & 5' - GAATTCTGTGAAGATAGTCGAAGAGATGTGGT- 3' \\
\hline PCR program & $\begin{array}{l}\text { Step } 1: 94{ }^{\circ} \mathrm{C}-3 \mathrm{~min} \text {, step } 2: 94{ }^{\circ} \mathrm{C}-45 \mathrm{~s} \text {, step } 3: 60{ }^{\circ} \mathrm{C}-45 \mathrm{~s} \text {, } \\
\text { step 4: } 72{ }^{\circ} \mathrm{C}-1 \mathrm{~min} \text { (steps } 2 \text { to } 4 \text { cycle } 35 \text { times); Step } 5: 72{ }^{\circ} \mathrm{C}-5 \mathrm{~min} \text {. }\end{array}$ \\
\hline \multicolumn{2}{|c|}{ 5-enolpyruvyl shikimate-3-phosphate synthase (EPSPS) aroA-CP4; expected product size: $507 \mathrm{bp}$} \\
\hline Primer 3 & 5' - ATGCTTCACGGTGCAAGCAGCCGTCCAGCA - 3' \\
\hline Primer 4 & 5' - GGTACCCTGTAGGTGATTGGCGTTGGAGTCTTT - 3' \\
\hline PCR Program & Conditions same as for the cry $3 \mathrm{~A}$ gene amplification \\
\hline \multicolumn{2}{|c|}{ Potato gene: adenosine 5'-triphophate synthase (ATPase control): expected product size: $300 \mathrm{bp}$} \\
\hline Primer 5 & 5' - CTTCTCCTTCTCAGCCGCCT - 3' \\
\hline Primer 6 & 5' - AGGGGGAGGATGGATAAACA - 3' \\
\hline PCR Program & $\begin{array}{l}\text { Step } 1: 94{ }^{\circ} \mathrm{C} \text { - } 3 \text { min., step } 2: 94{ }^{\circ} \mathrm{C}-45 \text { s., step 3: } 54{ }^{\circ} \mathrm{C} \text { - } 45 \text { s., } \\
\text { step 4: } 72{ }^{\circ} \mathrm{C}-45 \text { s.; (steps } 2 \text { to } 4 \text { cycle } 35 \text { times), step 5: } 72{ }^{\circ} \mathrm{C}-5 \text { min. }\end{array}$ \\
\hline
\end{tabular}

would be present. Having a reliable transformation system for clonal crops such as potato is especially important to maintain the genetic integrity of cultivars.

\subsection{Transformation efficiency and Cry3A expression levels}

Transformation and regeneration ability of different plant cultivars may vary significantly. The tissue culture conditions for the regeneration of potato plantlets from stem explants described in this paper were suitable for all three potato cultivars with different efficiency. All of the stem explants which were not inoculated with Agrobacterium produced plantlets when they were placed on a medium without glyphosate, and all of them died when they were placed on the selective medium with glyphosate. The first shoots on the explants inoculated with the Agrobacteruim culture appeared four weeks after their transfer to the $Z_{2}$ medium. Transformation frequency, measured as the percentage of explants forming shoots, was $7.4 \%$, $27.4 \%$ and $27.1 \%$ for the Kalina, Karol and Bor cultivars, respectively.

In total, one hundred and ten plants from the three cultivars were regenerated and tested by DAS-ELISA assay. The Cry3A expression levels varied across the transgenic lines, reaching up to $71.5 \mu \mathrm{g} / \mathrm{g}$ fresh weight. Twenty-one transgenic lines expressed the Cry $3 \mathrm{~A}$ protein at levels above $10 \mu \mathrm{g} / \mathrm{g}$ fresh weight, and the data is shown in Table II. These lines were used for beetle resistance studies (3 lines from cv. Kalina, 10 lines from cv. Koral and 8 lines from cv. Bor).

\subsection{Tuber yields and resistance to Colorado potato beetle in field conditions}

The field experiments carried out with twenty-one transgenic lines during the first and second year showed that all of the planted transgenic potato lines were resistant to beetle infestation. No visible damage caused by the beetle was observed on the transgenic plants grown at all three of the different locations. A relatively high level of Colorado potato beetle infestation was observed on the nontransgenic plants in all tested sites. All control plants were severely defoliated after beetle infestation (Fig. 2). Occasionally, a single beetle insect could be seen on some transgenic plants over the course of the growing season in the different fields. The plants from all of the tested transgenic lines were highly protected, and no damaged leaves were observed. We concluded that the expression level in the selected transgenic lines was high enough to provide good Colorado potato beetle resistance in the field conditions. According to Lawson et al. (2001), all the plants of the Russet Burbank potato expressing at least $10 \mu \mathrm{g} / \mathrm{g}$ fresh weight of Cry3A protein showed complete protection from foliar beetle damage.

During the second year of field testing, the transgenic lines showed high levels of resistance to Colorado potato beetle at both the Samokov and Negovan locations. The abundant presence of beetles on the control plants, which caused almost complete defoliation, and the minor presence and lack of any feeding damage on the transgenic plants was observed. The first and second year's field experiments clearly indicated that the resistance to the beetle in the three potato cultivars expressing the Cry3A protein was effective.

The transgenic potato yield studies were designed to select the best lines from each cultivar and not to compare them with nontransgenic parental lines. The first year of field trials was used to get a general assessment of line quality and to produce quality tuber seed for the larger experiment during the second year of testing. The tuber yield measured from each cluster and the average yield from each line grown at both locations are shown in Table II. During the first year of field trials, the tuber yields per plant from cv. Kalina were low because of the late planting and the fact that the transplants had not yet fully adapted to the soil (Tab. II). There was also a clear difference 
Table II. Cry3A content and tuber yield production from two years of field experiments.

\begin{tabular}{|c|c|c|c|}
\hline \multirow{2}{*}{ Cultivar/Transgenic line } & \multirow{2}{*}{ Cry3A $\mu \mathrm{g} / \mathrm{g}$ fresh weight (ppm) } & \multicolumn{2}{|c|}{ Average yield from 1 plant from 2 replicates $(\mathrm{kg})$} \\
\hline & & First year & Second year \\
\hline \multicolumn{4}{|l|}{ Kalina } \\
\hline $\mathbf{2}_{18 *}$ & $22.35 \pm 0.47$ & $0.40^{a}$ & $0.56^{b}$ \\
\hline $\mathbf{2}_{98}$ & $37.40 \pm 0.37$ & $0.45^{a}$ & $0.63^{a}$ \\
\hline $22_{100}$ & $20.20 \pm 0.24$ & $0.40^{a}$ & $0.61^{a}$ \\
\hline Average yield \pm SD & - & $0.42 \pm 0.03^{a}$ & $0.60 \pm 0.04^{a}$ \\
\hline Control & 0.0 & $0.26 \pm 0.02^{b}$ & $0.43 \pm 0.09^{b}$ \\
\hline \multicolumn{4}{|l|}{ Koral } \\
\hline $3_{1}$ & $31.60 \pm 2.62$ & $0.52^{a}$ & $0.76^{a}$ \\
\hline $\mathbf{3}_{12}$ & $28.50 \pm 0.38$ & $0.66^{a}$ & $0.84^{a}$ \\
\hline $3_{114}$ & $71.50 \pm 0.65$ & $0.53^{a}$ & $0.67^{a}$ \\
\hline $3_{115}$ & $28.55 \pm 0.16$ & $0.54^{a}$ & $0.68^{a}$ \\
\hline $\mathbf{3}_{116}$ & $38.00 \pm 0.21$ & $0.57^{a}$ & $0.78^{a}$ \\
\hline $3_{166}$ & $17.10 \pm 0.09$ & $0.55^{a}$ & $0.76^{a}$ \\
\hline $3_{185}$ & $46.50 \pm 2.51$ & $0.50^{a}$ & $0.63^{b}$ \\
\hline $\mathbf{3}_{203}$ & $34.00 \pm 1.73$ & $0.72^{a}$ & $0.95^{a}$ \\
\hline $3_{205}$ & $23.00 \pm 1.37$ & $0.40^{a}$ & $0.65^{a}$ \\
\hline $3_{206}$ & $51.75 \pm 1.70$ & $0.62^{a}$ & $0.87^{a}$ \\
\hline Average yield \pm SD & - & $0.56 \pm 0.09^{a}$ & $0.76 \pm 0.10^{a}$ \\
\hline Control & 0.0 & $0.28 \pm 0.02^{b}$ & $0.43 \pm 0.09^{b}$ \\
\hline \multicolumn{4}{|l|}{ Bor } \\
\hline $4_{1}$ & $10.15 \pm 0.24$ & $0.45^{a}$ & $0.27^{b}$ \\
\hline $\mathbf{4}_{41}$ & $12.05 \pm 0.25$ & $0.84^{a}$ & $1.29^{a}$ \\
\hline $4_{66}$ & $11.35 \pm 0.52$ & $0.23^{b}$ & $0.51^{b}$ \\
\hline $4_{100}$ & $16.00 \pm 0.16$ & $0.37^{a}$ & $0.50^{b}$ \\
\hline $\mathbf{4}_{103}$ & $19.00 \pm 0.07$ & $0.85^{a}$ & $1.25^{a}$ \\
\hline $4_{206}$ & $23.00 \pm 0.08$ & $0.67^{a}$ & $0.81^{a}$ \\
\hline $4_{236}$ & $53.00 \pm 0.10$ & $0.49^{a}$ & $0.65^{b}$ \\
\hline $4_{270}$ & $16.55 \pm 1.32$ & $0.23^{b}$ & $0.24^{b}$ \\
\hline $\mathrm{LS}$ mean $\pm \mathrm{SD}$ & - & $0.52 \pm 0.05^{a}$ & $0.69 \pm 0.40^{b}$ \\
\hline Control & 0.0 & $0.24 \pm 0.04^{b}$ & $0.26 \pm 0.09^{b}$ \\
\hline
\end{tabular}

* Transgenic lines marked in bold were selected for future studies. Lines that are significantly similar are marked with the same letter $\left({ }^{a}\right.$ or $\left.{ }^{b}\right)$, lines that are significantly different are marked with a different letter; SD $=$ standard deviation.

among the plants grown at the different locations. The plants from all of the tested lines developed better in Samokov, situated at a higher altitude, than in Kostinbrod. For example, the Kalina $2_{98}$ line was found to be the best-yielding line at the Samokov location with an average yield of $0.61 \mathrm{~kg}$ per cluster, but the worst at the Kostinbrod location with an average yield of $0.19 \mathrm{~kg}$ per cluster (data not shown).

During the second year of field tests the average tuber production from one plant from two replicates was $80-100 \%$ higher compared with the tuber production of the control, nontransgenic lines of the respective cultivar (Tab. II). Several lines, such as $3_{12}, 3_{203}$ and $3_{206}$, produced tuber amounts twice as great as that of the control nontransgenic plants $(0.84,0.95$ and $0.87 \mathrm{~kg}$, respectively, average yield from 1 plant from 2 replicates versus $0.43 \mathrm{~kg}$ for the control), while the tuber production of several other transgenic lines from cv. Bor $\left(4_{41}\right.$ and $4_{103}$ ) was even three to four times higher compared with the control, nontransgenic plants $(1.29$ and $1.25 \mathrm{~kg}$, respectively, versus $0.26 \mathrm{~kg}$ for the control). The severe infestation of the control plots by Colorado potato beetle could be the reason for that difference. In the future, we plan to evaluate the yield

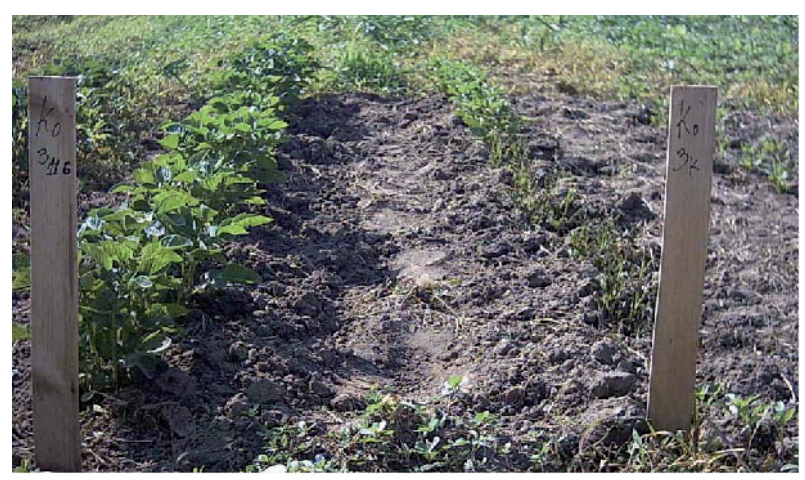

Figure 2. Field resistance of the transgenic line $3_{116}$ of cv. Koral (left) to Colorado potato beetle and leaf defoliation caused by the beetle on nontransgenic plants from the same cultivar.

of selected transgenic lines in comparison with their nontransgenic controls in fields where beetles will be controlled by insecticides.

Infestation by Colorado potato beetles clearly affected yield of nontransgenic control plants. In most cases, no damage to 


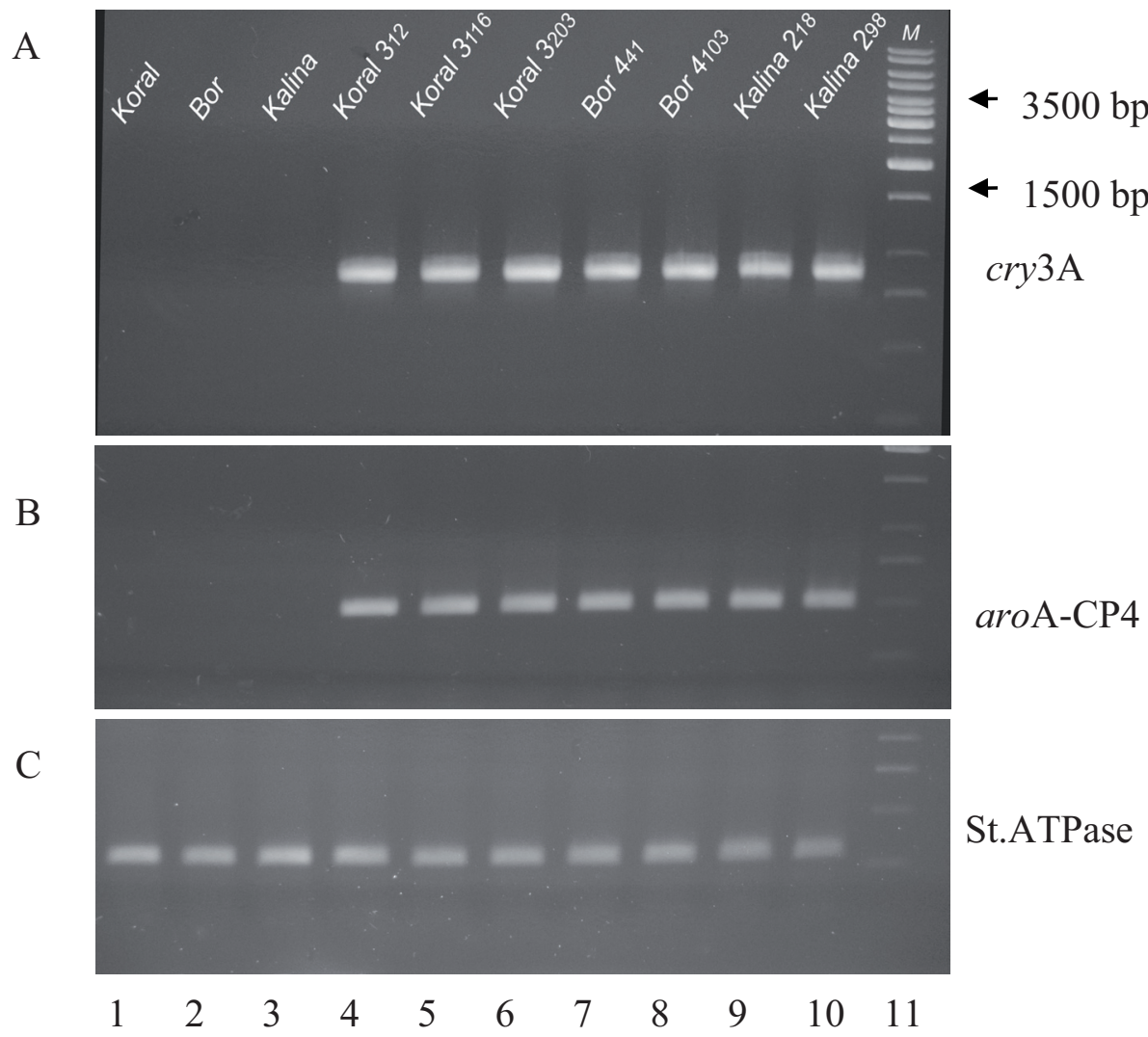

Figure 3. PCR analysis of the transgenic lines that performed best, showing the presence of transgene in the genome. A. An 874 bp PCR product of the cry3A. B. A 507 bp PCR product of aroA-CP4. C. PCR with primers for potato St.ATP-ase positive control producing 300 bp products. Lanes 1-3 nontransgenic controls of cv. Koral, Bor and Kalina. Lanes 4-6 transgenic lines of cv. Koral ( $3_{12}$, $3_{116}$ and $3_{203}$, respectively), lanes 7 and 8 transgenic lines of cv. Bor $\left(4_{41}\right.$ and $4_{103}$, respectively), lanes 9 and 10 transgenic lines of cv. Kalina ( $2_{18}$ and $2_{98}$, respectively) and lane 11 - GeneRuler ${ }^{T M} 1 \mathrm{~kb}$ DNA Leader (Fermentas).

foliage in transgenic plants resulted in significant yield advantage. The best yield results were obtained for transgenic lines from the Koral cultivar, where all but one line showed significantly higher yield during two years of testing. Most variation in yield data was seen for transgenic lines from the Bor cultivar, where only three from eight transgenic lines show significantly higher yield in two years of testing.

The morphological and agronomic comparison of the tested transgenic lines, including variety type and uniformity, resistance, and the yield from two years of field experiments, allowed the selection of the most promising 2-3 lines per cultivar. The lines $2_{18}$ and 298 (cv. Kalina), lines $3_{12}, 3_{116}$ and $3_{203}$ (cv. Koral), and lines $4_{41}$ and $4_{103}$ (cv. Bor) were selected. During the third year of field trials these lines were grown for mass propagation for future commercial use at one location (Samokov) and also to gather more accurate information about the morphology of the selected lines. In the third year of field tests the plants from the selected seven lines did not show any change in their resistance to Colorado potato beetle observed during the first and second years of field tests. There was no plant damage seen across the transgenic plots and there was an abundant presence of the beetle on the nontransgenic control plants. The level of Cry3A protein in the lines that performed best stayed at a similar level when the samples from field- grown plants were measured during the third year of the experiment (data not shown). Transgenic potato Russet Burbank plants expressing a synthetic Bt gene and exhibiting strong resistance to Colorado potato beetle in field trials have been produced (Perlak et al., 1993) and have been approved for commercial release in the USA.

Three different potato cultivars that are very popular on the Bulgarian market have been transformed and tested for resistance to Colorado potato beetle. Transgenic potato plants expressing a synthetic Bt gene exhibited strong resistance to Colorado potato beetle in the field trials. However, the regulatory procedures for transgenic potato commercial release are still not in place in Bulgaria.

\subsection{PCR results of the best-performing transgenic lines}

The presence of cry3A and aroA-CP4 genes in the seven lines that performed best was confirmed by PCR analysis (Fig. 3). All tested lines were positive for the cry3A toxin gene and the aroA-CP4 selectable marker gene, as well as for the native potato gene used as a positive control. 
Table III. Mortality rates of the four larval stages of the Colorado potato beetle fed on the leaves of Bulgarian potato cultivars transformed with the cry3 A gene and nontransgenic plants.

\begin{tabular}{cccc}
\hline Stage & Line & Mortality rate (\%) & $\begin{array}{c}\text { Number of larvae } \\
\text { used in assay }\end{array}$ \\
\hline 1st instars & Control & 4 & 70 \\
& $2_{18}$ & 100 & 181 \\
& $3_{12}$ & 100 & 130 \\
2nd instars & $4_{41}$ & 100 & 180 \\
& Control & 8 & 67 \\
& $2_{18}$ & 100 & 42 \\
& $3_{12}$ & 100 & 31 \\
& $4_{41}$ & 100 & 81 \\
3rd instars & & & 62 \\
& Control & 6 & 44 \\
& $2_{18}$ & 100 & 31 \\
& $3_{12}$ & 100 & 30 \\
& $4_{41}$ & 100 & 58 \\
& & & 40 \\
& Control & 10 & 43 \\
& $2_{18}$ & 100 & 35 \\
& $3_{12}$ & 100 & 100 \\
\hline
\end{tabular}

\subsection{Insect bioassays}

The results from the insect bioassay experiment summarized in Table III showed that the consumption of the foliage of the potatoes transformed with the cry3A gene was greatly influenced by the developmental stage of the Colorado potato beetle larvae tested. The youngest larvae (first instars) were especially susceptible. Feeding on foliage which contained the Cry3A protein resulted in $100 \%$ mortality rates after $3-4$ days. The same rate of beetle larval mortality was reported for Superior Newleaf ${ }^{(R)}$ potato leaves containing the same expression vector after one day of feeding (Kalushkov and Batchvarova, 2005). The larval mortality of the second, third and fourth instars was also $100 \%$ but, as expected, they lived longer as compared with the first instar. This could be explained by the differences in their energetic reserves, which are higher for the older larvae. Gilliland et al. (2002) reported that in many cases larvae become less susceptible to $\delta$ endotoxins as they age due to fewer binding sites in the older larvae.

All three tested transgenic lines were highly effective against beetle larvae, leading to reduction of Colorado potato beetle populations. Also, the transgenic leaves were almost undamaged, in contrast to the control leaves, which sustained feeding damage. In addition, there was a great difference in weight between the larvae fed on transgenic leaves and those fed on nontransgenic leaves (Fig. 4). Moreover, studies in laboratory conditions carried out with the Bulgarian Bt potato cultivars described in this paper have shown that the cry3A expression has had no negative effect on aphid Myzus persicae development and reproduction (Kalushkov et al., 2006). It has been reported that the $B t$ Cry $3 \mathrm{~A}$ toxin is highly specific to
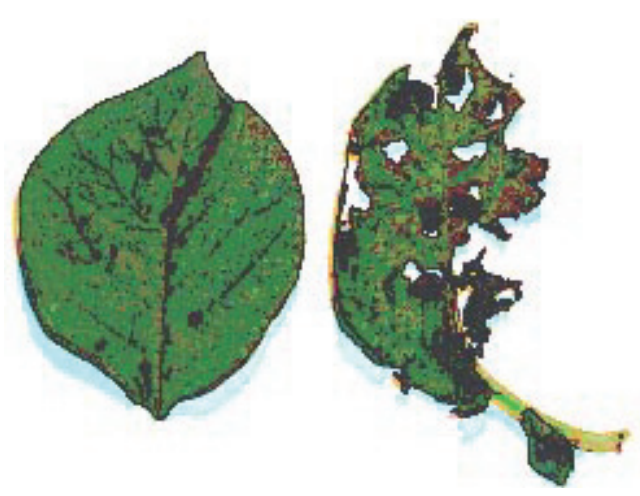

Figure 4. Insect bioassay experiment showing the larvae of the Colorado potato beetle on a leaf from a transgenic plant (line $3_{12}$ of cv. Koral) (left) and on a leaf from a control, nontransgenic plant (right).

Colorado potato beetle larvae and the cultivation of transgenic potato presents a low risk to other coleopteran insects (Ferry et al., 2007).

\section{CONCLUSION}

For many farmers in Bulgaria potato represents a staple food and an important cash crop. Each year, the potato growers lose a significant amount of their crops due to Colorado potato beetle. At the present time, the control of the beetle in the country is accomplished primarily by the use of chemical insecticides. Here, we described the production of the first transgenic potatoes through the incorporation of a gene for the Bacillus thuringiensis protein into three valuable and widely grown, commercial Bulgarian potato cultivars. The results from the three years of field trials demonstrated that Kalina, Koral and Bor potato plants were highly effective in suppressing populations of Colarado potato beetle. The transgenic Bt-expressing potatoes exhibited season-long control of all stages of $\mathrm{CPB}$, and provided greater protection from defoliation.

The morphology and agronomic properties of selected lines of the three cultivars were comparable with the parental varieties. The cry3 A gene and aro $\mathrm{A}-\mathrm{CP} 4$ gene showed stable inheritance as demonstrated by resistance tests, ELISA and PCR.

The tuber yield from several best-performing transgenic lines under field conditions from the tree cultivars was 80 $100 \%$ higher compared with that of the control, nontransgenic lines.

Additionally, the bioassay testing of the best-performing lines from each cultivar showed $100 \%$ mortality of the Colorado potato beetle larvae from all developmental stages.

Genetically modified crops may contribute to increased productivity and reduction of costs in sustainable agriculture. It is expected that the use of transgenic resistant potato cultivars will reduce the use of environmentally undesirable insecticides. According to the Bulgarian Ministry of Agriculture and Forestry, potato was grown on more then 23 thousand 
ha during 2007 and the total amount of insecticides used was about 9.5 thousand liters.

Our results suggest that the genetically improved, insectresistant potato cultivars could have a positive impact on sustainable, ecologically safe and economically efficient agriculture in Bulgaria. However, the acceptance of transgenic agricultural products in Europe is still under review, with no clear prospects for commercial release in the near future.

Acknowledgements: We thank Monsanto for providing the vector pMON38943 and Alina Flasinska for her copyediting of the later drafts of the manuscript.

\section{REFERENCES}

Arpaia S., Mennella G., Onofaro V., Perri E., Sunseri F., Rotino G. (1997) Production of transgenic eggplant (Solanum melongena L.) resistant to Colorado Potato Beetle (Leptinotarsa decemlineata Say), Theor. Appl. Genet. 95, 329-334.

Benedict J.H., Sachs E.S., Altman D.W., Deaton W.R., Kohel R.J., Ring D.R., Berberich S.A. (1996) Field performance of cottons expressing transgenic CryIA insecticidal proteins for resistance to Heliothis virescens and Helicoverpa zea (Lepidoptera: Noctuidae), J. Econ. Entomol. 89, 230-238.

Dellaporta S.L., Wood J., Hicks J.B. (1983) A plant DNA minipreparation: Version II, Plant Mol. Biol. Rep. 1, 19-21.

Dimitrova L., Blagoeva V. (1998) Firma and Bor, new Bulgarian potato varieties. International Symposium: "Breeding research on potatoes". Rostock, Germany, June 23-26, pp. 34-46.

Duncan D.R., Hammond D., Zalewski J., Cudnohufsky J., Kaniewski W., Thornton M., Bookout J.T., Lavrik P., Rogan G.J., Feldman-Riebe J. (2002) Field performance of transgenic potato, with resistance to Colorado potato beetle and viruses, Hort. Sci. 37, 275-276.

Ferry N., Mulligan E.A., Majerus M.E.N., Gatehouse A.M.R. (2007) Bitrophic and tritrophic effects of Bt Cry3 A transgenic potato on beneficial, non-target, beetles, Transgenic Res. 16, 795-812.

Forgash A.J. (1985) Insecticide resistance in the Colorado potato beetle. Research Bulletin, Massachusetts Agricultural Experiment Station $704,33-52$.
Gilliland A., Chambers C.E., Bone E.J., Ellar D.J. (2002) Role of Bacillus thuringiensis Cry1 delta endotoxin binding in determining potency during lepidopteran larval development, Appl. Environ. Microb. 68, 1509-1515.

Hamilton G.C., Jelenkovic G.L., Lashomb J.H., Ghidiu G., Billings S., Patt J.M. (1997) Effectiveness of transgenic eggplant (Solanum melongena L.) against the Colorado potato beetle, Adv. Hort. Sci. 11, 189-192.

Jansens S., van Vliet A., Dickburt C., Buysse L., Piens C., Saey B., de Wulf A., Gossele V., Paez A., Gobel E., Peferoen M. (1997) Transgenic corn expressing a Cry9C insecticidal protein from Bacillus thuringiensis protected from European corn borer damage, Crop Sci. 37, 1616-1624.

Kalushkov P., Batchvarova R. (2005) Effectiveness of Bt NewLeaf ${ }^{\circledR}$ potato to control Leptinotarsa decemlineata (Say) (Coleoptera: Chrysomelidae) in Bulgaria, Biotechnol. Biotec. Eq. 19, 28-34.

Kalushkov P., Tzankova R., Stoeva P., Batchvarova R., Vlahova M., Slavov S., Radkova M. (2006) Ecological investigations on the effect of Bulgarian FM plants on the arthropod fauna. GMOs in Integrated Plant protection, OILB WPRS Bulletin 29, 85-90.

Kaniewski W.K., Thomas P.E. (1999) Field testing for virus resistance and agronomic performance in transgenic plants, Mol. Biotechnol. $12,101-115$.

Kaniewski W.K., Thomas P.E. (2004) The potato story, AgBio Forum 7, $41-46$.

Lawson E.C., Weiss J.D., Thomas P.E., Kaniewski W.K. (2001) NewLeaf Plus ${ }^{\circledR}$ Russet Burbank potatoes: replicase-mediated resistance to potato leafroll virus, Mol. Breeding 7, 1-12.

Murashige T., Skoog F. (1962) A revised medium for rapid growth and bioassays with tobacco tissue cultures, Physiol. Plant 15, 473-497.

Newell C.A., Rozman R., Hinchee M.A., Lawson E.C., Haley L., Sanders P., Kaniewski W., Tumer N.E., Horsch R.B., Fraley R.T. (1991) Agrobacterium-mediated transformation of Solanum tuberosum L. cv. 'Russet Burbank', Plant Cell Rep. 10, 30-34.

Perlak F.J., Stone T.B., Muskopf Y.M., Petersen L.J., Parker G.B., McPherson S.A., Wyman J., Love S., Reed G., Biever D., Fischhoff D.A. (1993) Genetically improved potatoes: protection from damage by Colorado potato beetles, Plant Mol. Biol. 22, 313-321.

Roush R.T. (1994) Managing pests and their resistance to Bacillus thuringiensis: can transgenic crops be better than sprays? Biocontrol Sci. Techn. 4, 501-516. 